\title{
Corrigendum: Transduction as a Potential Dissemination Mechanism of a Clonal qnrB19-Carrying Plasmid Isolated From Salmonella of Multiple Serotypes and Isolation Sources
}

\author{
Andrea I. Moreno-Switt ${ }^{1,2}$, David Pezoa ${ }^{3}$, Vanessa Sepúlveda ${ }^{3}$, Iván González ${ }^{3}$, \\ Dácil Rivera ${ }^{1}$, Patricio Retamal ${ }^{4}$, Paola Navarrete ${ }^{5,6}$, Angélica Reyes-Jara ${ }^{5}$ and \\ Magaly Toro ${ }^{5 *}$
}

${ }^{1}$ Escuela de Medicina Veterinaria, Facultad de Ciencias de la Vida, Universidad Andres Bello, Santiago, Chile, ${ }^{2}$ Millennium Initiative for Collaborative Research on Bacterial Resistance (MICROB-R), Santiago, Chile, ${ }^{3}$ Facultad de Ciencias, Escuela de Medicina Veterinaria, Universidad Mayor, Santiago, Chile, ${ }^{4}$ Departamento de Medicina Preventiva Animal, Facultad de Ciencias Veterinarias y Pecuarias, Universidad de Chile, Santiago, Chile, ${ }^{5}$ Laboratorio de Microbiología y Probióticos, Instituto de Nutrición y Tecnología de los Alimentos (INTA), Universidad de Chile, Santiago, Chile, ${ }^{6}$ Millennium Nucleus in the Biology of Intestinal Microbiota, Santiago, Chile

Keywords: antimicrobial resistance, foodborne diseases, plasmid, quinolones, qnrB19, Salmonella spp., Chile, plasmid-mediated quinolone resistance

\section{OPEN ACCESS}

Edited and reviewed by: Benjamin Andrew Evans, University of East Anglia, United Kingdom

*Correspondence: Magaly Toro magaly.toro@inta.uchile.cl

Specialty section: This article was submitted to Antimicrobials, Resistance and

Chemotherapy,

a section of the journal

Frontiers in Microbiology

Received: 13 February 2020

Accepted: 13 March 2020

Published: 07 April 2020

Citation:

Moreno-Switt Al, Pezoa D, Sepúlveda V, González I, Rivera D, Retamal P, Navarrete P, Reyes-Jara A and Toro M (2020) Corrigendum:

Transduction as a Potential

Dissemination Mechanism of a Clonal qnrB19-Carrying Plasmid Isolated From Salmonella of Multiple Serotypes and Isolation Sources.

Front. Microbiol. 11:547. doi: 10.3389/fmicb.2020.00547

\section{A Corrigendum on}

Transduction as a Potential Dissemination Mechanism of a Clonal qnrB19-Carrying Plasmid Isolated From Salmonella of Multiple Serotypes and Isolation Sources

by Moreno-Switt, AI., Pezoa, D., Sepúlveda, V., González, I., Rivera, D., Retamal, P., et al. (2019). Front. Microbiol. 10:2503. doi: 10.3389/fmicb.2019.02503

In the original article, "Andres et al. (2013)" was not cited and referenced in the article. The citation has now been inserted in the Introduction, paragraph three and in the Discussion section, paragraph four and should read:

"Antimicrobial resistance to quinolones can be the result of target mutations reducing the drug's binding to the enzymes gyrase or topoisomerase IV (Hooper and Jacoby, 2016). Additionally, genes harbored in plasmids - such as qnr genes-codify for proteins that protect the target enzymes from quinolone action in the phenomena known as plasmid-mediated quinolone resistance (PMQR) (Hooper and Jacoby, 2016). The presence of antimicrobial resistance genes in plasmids is of great concern from a public health perspective because they can easily spread from one bacterium to another through horizontal gene transfer (Rozwandowicz et al., 2018). Three small plasmids carrying the gene $q n r B$ have been described since 2010 in South America (Pallecchi et al., 2009; Tran et al., 2012; Cordeiro et al., 2016). The plasmids were obtained from bacteria isolated in Colombia, Peru, and Argentina, and their sizes ranged from 2,699 to 2,750 bp (Karczmarczyk et al., 2010; Pallecchi et al., 2010; Tran et al., 2012). Moreover, some of them can be transferred by conjugation (Andres et al., 2013). Recently, similar plasmids have also been reported in Europe and North America in Salmonella isolated from poultry (Fiegen et al., 2017; Tyson et al., 2017).”

and

"The widespread presence of pPAB19-4-like plasmids among diverse Salmonella serotypes, hosts, years, and geographic locations poses a risk for global human and animal populations. A better understanding of the mechanism involved in the spread of these plasmids could be used 
to understand their dissemination in the environment. Since unrelated Salmonella serotypes and E. coli have carried identical plasmids, it was plausible to think that horizontal gene transfer mechanisms were involved on their dissemination. The pPAB194 plasmid is small $(2.7 \mathrm{~kb})$ and lacks mob and tra genes, therefore, self-conjugation is not possible (Tran et al., 2012); for this reason, we did not include DNAse treatment in our experiments. A similar plasmid (pPAB19-2) was transferred by conjugation (Andres et al., 2013), suggesting that more than one mechanism of horizontal gene transfer is possible in these types of plasmids. Our results demonstrated that pPAB19-4 plasmids

\section{REFERENCES}

Andres, P., Lucero, C., Soler-Bistué, A., Guerriero, L., Albornoz, E., Tran, T., et al. (2013). Differential distribution of plasmid-mediated quinolone resistance genes in clinical enterobacteria with unusual phenotypes of quinolone susceptibility from Argentina. Antimicrob Agents Chemother. 57, 2467-2475. doi: 10.1128/AAC.01615-12

Cordeiro, N. F., Nabón, A., García-Fulgueiras, V., Álvez, M., Sirok, A., Camou, T., et al. (2016). Analysis of plasmid-mediated quinolone and oxyimino-cephalosporin resistance mechanisms in Uruguayan Salmonella enterica isolates from 2011-2013. J. Glob. Antimicrob. Resist. 6, 165-171. doi: 10.1016/j.jgar.2016.06.002

Fiegen, U., Klein, G., de Jong, A., and Kehrenberg, C. (2017). Detection of a novel qnrB19-carrying plasmid variant mediating decreased Fluoroquinolone susceptibility in Salmonella enterica Serovar Hadar. Microb. Drug Resist. 23, 280-284. doi: 10.1089/mdr.2016 .0067

Hooper, D. C., and Jacoby, G. A. (2016). Topoisomerase inhibitors: fluoroquinolone mechanisms of action and resistance. Cold Spring Harb. Perspect. Med. 6, 1-21. doi: 10.1101/cshperspect.a025320

Karczmarczyk, M., Martins, M., McCusker, M., Mattar, S., Amaral, L., Leonard, N., et al. (2010). Characterization of antimicrobial resistance in Salmonella enterica food and animal isolates from Colombia: identification of a qnrB19-mediated quinolone resistance marker in two novel serovars. FEMS Microbiol. Lett. 313, 10-19. doi: 10.1111/j.1574-6968.2010.02119.x

Mašlanová, I., Stríbná, S., Doškar, J., and Pantuček, R. (2016). Efficient plasmid transduction to Staphylococcus aureus strains insensitive to the lytic action of transducing phage. FEMS Microbiol. Lett. 363, 1-7. doi: 10.1093/femsle/fnw211

Pallecchi, L., Riccobono, E., Mantella, A., Bartalesi, F., Sennati, S., Gamboa, H., et al. (2009). High prevalence of qnr genes in commensal enterobacteria can be transferred from $S$. Heidelberg to $S$. Typhimurium by transduction assisted by a P22 bacteriophage. Transduction frequency reported in the current study (1 transducent in $10^{6}$ phage) is similar to that reported in previous studies (Mašlanová et al., 2016; Varga et al., 2016). Importantly, our study shows transduction in experimental conditions, indicating that transduction is another plausible mechanism for pPAB19-4-like plasmids spread in the environment."

The authors apologize for this error and state that this does not change the scientific conclusions of the article in any way. The original article has been updated. from healthy children in Peru and Bolivia. Antimicrob. Agents Chemother. 53, 2632-2635. doi: 10.1128/AAC.01722-08

Pallecchi, L., Riccobono, E., Sennati, S., Mantella, A., Bartalesi, F., Trigoso, C., et al. (2010). Characterization of small ColE-like plasmids mediating widespread dissemination of the qnrB19 gene in commensal enterobacteria. Antimicrob. Agents Chemother. 54, 678-682. doi: 10.1128/AAC.01160-09

Rozwandowicz, M., Brouwer, M. S. M., Fischer, J., Wagenaar, J. A., GonzalezZorn, B., Guerra, B., et al. (2018). Plasmids carrying antimicrobial resistance genes in Enterobacteriaceae. J. Antimicrob. Chemother. 73, 1121-1137. doi: $10.1093 / \mathrm{jac} / \mathrm{dkx} 488$

Tran, T., Andres, P., Petroni, A., Soler-Bistué, A., Albornoz, E., Zorreguieta, A., et al. (2012). Small plasmids harboring qnrB19: a model for plasmid evolution mediated by site-specific recombination at oriT and Xer sites. Antimicrob. Agents Chemother. 56, 1821-1827. doi: 10.1128/AAC.06036-11

Tyson, G. H., Tate, H. P., Zhao, S., Li, C., Dessai, U., Simmons, M., et al. (2017). Identification of plasmid-mediated quinolone resistance in Salmonella isolated from swine ceca and retail pork chops in the United States. Antimicrob. Agents Chemother. 61, pii: e01318-17. doi: 10.1128/AAC.01318-17

Varga, M., Pantuček, R., RuŽičková, V., and Doškar, J. (2016). Molecular characterization of a new efficiently transducing bacteriophage identified in meticillin-resistant Staphylococcus aureus. J. Gen. Virol. 97, 258-268. doi: 10.1099/jgv.0.000329

Copyright (๑) 2020 Moreno-Switt, Pezoa, Sepúlveda, González, Rivera, Retamal, Navarrete, Reyes-Jara and Toro. This is an open-access article distributed under the terms of the Creative Commons Attribution License (CC BY). The use, distribution or reproduction in other forums is permitted, provided the original author $(s)$ and the copyright owner(s) are credited and that the original publication in this journal is cited, in accordance with accepted academic practice. No use, distribution or reproduction is permitted which does not comply with these terms. 